\title{
Value of medical practice guidelines questioned
}

Published at www.cmaj.ca on Jan. 21

$\mathrm{T}$ he use of medical guidelines to inform primary health care decision-making surfaced as a point of unexpected disagreement among Canadian and international experts gathered at a Canadian Institute of Health Research (CIHR) Primary Care Summit in Toronto, Ontario, in January.

Opinions on the value of practice guidelines, which have proliferated exponentially in recent years, are increasingly strident, Dr. Janusz Kaczorowski, research director for the Department of Family Practice at the University of British Columbia in Vancouver, told the summit. Worldwide, up to 4000 practice guidelines are produced annually, he added.

In Canada, the Canadian Medical Association's InfoBase now contains more than 1200 practice guidelines, with 74 available for the management of cardiovascular illnesses alone, Kaczorowski said. "Primary health care providers are expected to be up to date on everything. But the amount of information is unmanageable. And not all guidelines are created equal. Very frequently, there are poor recommendations based on substandard evidence."

Earlier, two primary health researchers warned that guidelines can spell serious and systematic trouble for both patients and primary care providers.

"Guideline-driven care can be worse for patient outcomes," said Dr. Dee Mangin, director of primary care research in the Department of Public Health and General Practice at the University of Otago in Christchurch, New Zealand. "Guidelines are not evidencebased medicine."

"There are real reasons for disregarding guidelines," added Dr. Barbara Starfield, professor of health policy and management at the Bloomberg School of Public Health at Johns Hopkins University in Baltimore, Maryland. "Diseases are not homogeneous activities," she said. "Management

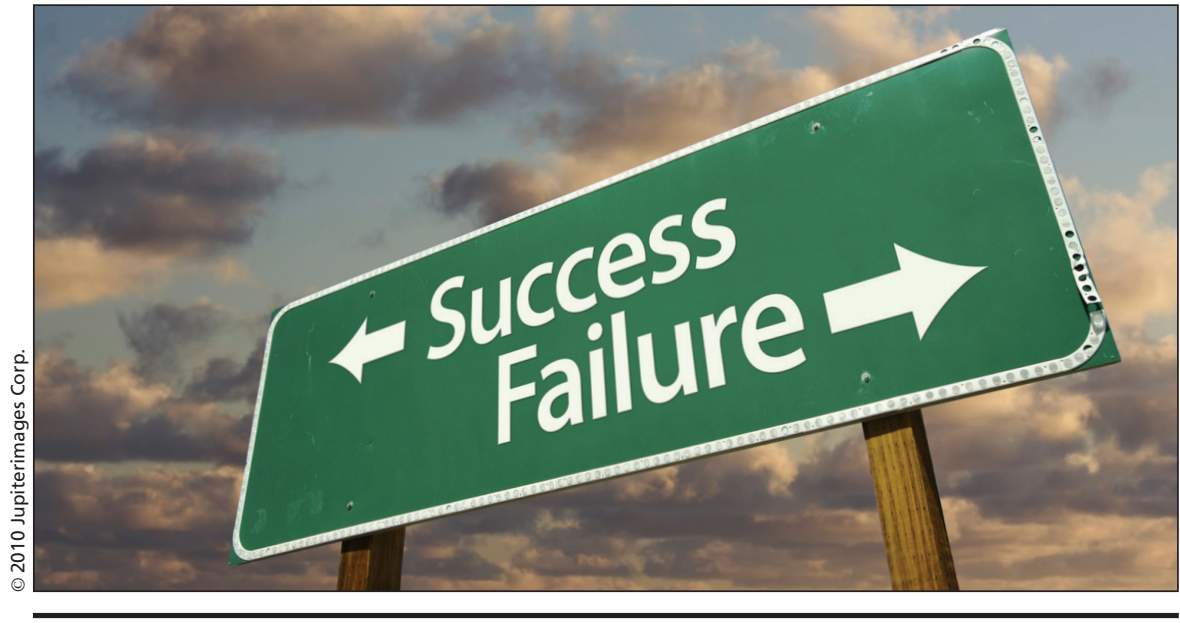

Opinions differ on the net impact of standardized disease treatment guidelines.

focused on diseases does not always improve primary care."

Mangin, while warning that guidelines have promoted a standardization of care that may encourage primary care practitioners to overlook patients' overall burden of chronic diseases, noted that about half of patients over age 65 in wealthy nations have at least three chronic conditions. That often leads physicians to prescribe multiple, and not always mutually compatible, drug regimes, a practice known as polypharmacy, she said.

"Polypharmacy has itself now become a major disease," Mangin warned. "Old age has become a time of great pharmacological peril."

Mangin also surmised that as many as four of five guideline contributors have conflicts of interest, further eroding the value of the guidelines; and described scenarios in which drug treatment guidelines "coerce doctors to coerce patients to comply."

"The challenge," she said, "is not overpowering physician judgment with guidelines that should offer guidance to inform practice, rather than to drive it."

While linking treatment guidelines to overuse and misue of pharmaceuticals, Starfield argued that "polypharmacy rates are an indicator of poor quality primary health care."
Several delegates bristled at the challenge to the value of most guidelines.

"As a clinical practice guideline developer, we're not looking for people to follow the guidelines, we're looking for people to consider the guidelines," said Dr. Doug Stich, program director of Alberta's Toward Optimized Practice Program.

Others defended the expertise that guideline developers bring to the table.

"With as many as half of all patients over 65 having five or more chronic conditions, multimorbidity is more the rule than the exception, and physicians don't have the expertise to evaluate the guidelines," argued Dr. Denis Drouin, clinical professor of family medicine at Laval University in Québec City, Quebec, while describing his involvement in an initiative funded by the CIHR and the Public Health Agency of Canada to develop a "meta-guideline" that aims to synthesize the numerous cardiovascular disease treatment guidelines.

"More and more people are treating chronic conditions, including pharmacists and nurses. They need standardized guidelines," Drouin said. "Standardization promotes good care." - Paul Christopher Webster, Toronto, Ont.

DOI:10.1503/cmaj.109-3161 